\title{
Agregação e resistência à penetração de um Latossolo Vermelho sob sistema de integração lavoura-pecuária
}

\author{
Jolimar Antonio Schiavo $\left({ }^{1 *}\right)$; Gilberto Colodro $\left({ }^{2}\right)$ \\ (') Universidade Estadual de Mato Grosso do Sul (UEMS), Programa de Pós Graduação em Agronomia, Rodovia Aquidauana, km 12, \\ 79200-000 Aquidauana (MS), Brasil. \\ (2) Instituto Federal Goiano (IFG), Rodovia Sul Goiana, Km 1, 75901-970 Rio Verde (GO), Brasil. \\ (*) Autor correspondente: schiavo@uems.br
}

Recebido: 22/nov./2011; Aceito: 5/set./2012

\section{Resumo}

Objetivou-se neste trabalho avaliar alterações nos atributos físicos do solo, especificamente na agregação e resistência do solo à penetração, e carbono orgânico total (COT) de um Latossolo Vermelho sob sistema de integração lavoura-pecuária com as coberturas: milho, braquiária, Tanzânia e Cerrado. O solo sob cobertura de Tanzânia revelou menor porcentagem de poros totais (49\%); maior densidade do solo (Ds) na camada superficial de 0-5 cm (1,60 g kg-1); e semelhante ao solo cultivado com braquiária, menores porcentagens de macroporos (6,6\% a 9,4\%) e maiores valores de resistência à penetração do solo na capacidade de campo (1,3 a 4,08 MPa). Nas três profundidades, os teores de COT foram maiores na vegetação de Cerrado; especificamente na profundidade de 5-10 cm entre as áreas cultivadas observaram-se maiores teores na área com milho $\left(20,15 \mathrm{~g} \mathrm{~kg}^{-1}\right)$ e braquiária $\left(23,15 \mathrm{~g} \mathrm{~kg}^{-1}\right)$. Nas áreas com milho e braquiária ocorreram maior porcentagem de agregados maiores que $4 \mathrm{~mm}$, semelhante ao Cerrado, proporcionando os maiores diâmetros médios ponderados (DMP) de agregados. Houve correlação positiva entre os teores de COT e DMP de agregados ( $r=0,45)$, DMP e porosidade total do solo ( $r=0,76)$; $e$ negativa entre COT e Ds do solo $(r=-0,56)$.

Palavras-chave: atributos físicos do solo, plantio direto, qualidade física do solo, manejo do solo.

\section{Aggregation and penetration resistance of an Oxisol under livestock-crop integration system}

Abstract

The aim of this study was to evaluate changes in soil physical properties, specifically regarding soil aggregation and resistance to penetration, as well as total organic carbon (TOC) of an Oxisol subjected to an integrated crop-livestock system with the following coverage: corn, pasture, Tanzania grass and Savannah. Soil cultivated with Tanzania grass showed the lowest percentage of total porosity (49\%), highest density of soil (Ds) in the surface layer of $0-5 \mathrm{~cm}\left(1.60 \mathrm{~g} \mathrm{~kg}^{-1}\right)$, and similar to the soil cultivated with pasture, presented lower percentages of macropores (6.6 to 9.4\%) and higher values of soil penetration resistance at field capacity (1.3 to $4.08 \mathrm{MPa}$ ). At the three depths, the TOC levels were highest in Savannah soil; and among the cultivated areas at the depth of 5-10 cm, the highest levels were observed in areas with corn $\left(20.15 \mathrm{~g} \mathrm{~kg}^{-1}\right)$ and pasture $\left(23.15 \mathrm{~g} \mathrm{~kg}^{-1}\right)$. Areas with corn and pasture showed the highest percentage of large aggregates ( $\left.>4 \mathrm{~mm}\right)$, similar to the Savannah that presented the highest weighted average diameter of aggregates (WAD). A positive correlation was observed between TOC and WAD of the aggregates ( $r=0.45)$, WAD and total soil porosity $(r=0.76)$ and a negative correlation between TOC and Ds ( $r=-0.56)$.

Key words: soil physical properties, no-tillage, soil physical quality, soil management.

\section{INTRODUÇÃO}

Atualmente, sistemas mistos de exploração de lavoura e pecuária (integração lavoura - pecuária - ILP) têm sido preconizados, pois agregam vantagens em relação aos sistemas isolados de agricultura ou de pecuária. $\mathrm{O}$ sistema ILP tem-se tornado uma alternativa de uso da terra muito eficiente, pois, promove a recuperação e renovaçáo de pastagens, permite o uso racional dos insumos, diversifica a produção e mantém a produtividade agrícola de grãos (Spera et al., 2006; Balbinot Júnior et al., 2009), podendo também promover melhoria na qualidade física do solo (Salton et al., 2008).

No sistema ILP, sob o sistema de plantio direto, um dos principais benefícios está relacionado à formação de macroagregados estáveis, que são responsáveis pela estrutura do solo (MielniczuK et al., 2003; Salton et al., 2008); consequentemente, exercem influência nos 
demais atributos físicos do solo como porosidade (macro e microporosidade), velocidade de infiltração de água, densidade do solo, resistência do solo à penetração, etc.

A matéria orgânica do solo (MOS) possui estreita relação na formação dos agregados do solo (SALTON et al., 2008), atuando na formação de microagregados em função de sua ligação com os domínios de argilas orientadas, cátions polivalentes ( $\mathrm{Al}, \mathrm{Fe}$ e $\mathrm{Ca}$ ) e partículas de quartzo (Emerson, 1959; Edwards e Bremmner, 1967), os quais são unidos formando os macroagregados. Segundo SIX et al. (2004), em uma escala evolutiva, partículas primárias livres e agregados de tamanho de silte são unidos por agentes ligantes persistentes, como matéria orgânica humificada ou complexos com cátions polivalentes, óxidos e aluminossilicatos, formando os microagregados (20 a $250 \mu \mathrm{m}$ ). Esses microagregados estáveis são unidos por agentes ligantes temporários (raízes ou hifas de fungos) e transientes (polissacarídeos derivados de microrganismos ou plantas), resultando na formação dos macroagregados $(>250 \mu \mathrm{m})$. Dessa forma, os microagregados são classificados como mais estáveis e menos suscetíveis às práticas agrícolas de manejo do que os macroagregados.

No sistema ILP sob plantio direto, além da MOS incorporada continuamente na superfície do solo, sem revolvimento, o sistema radicular principalmente de plantas da família das Poaceae, exerce papel muito importante na formaçáo de agregados do solo (BRONICK e LAL, 2005; SALTON et al., 2008), bem como nos demais atributos físicos do solo.

Atributos do solo, tais como a densidade do solo, a porosidade, a condutividade hidráulica, a curva de retenção de água (BALBINo et al., 2004), a resistência do solo à penetração (IMHOFf et al., 2000) e a estabilidade de agregados (CORRÊA, 2002), têm sido utilizados frequentemente como indicadores de qualidade física, devido principalmente ao baixo custo e à facilidade de obtenção das medidas. Associado a este fato, tais atributos físicos do solo são sensíveis aos diferentes sistemas de manejo em um curto intervalo de tempo. No entanto, estudos sobre a utilização de sistemas com integração lavoura-pecuária e seu impacto sobre os atributos físicos do solo em áreas de Cerrado são bastante incipientes. Ainda, há de se considerar que pouco se conhece a respeito de quais espécies de gramíneas seriam mais adaptadas na sucessão ou rotação das culturas agrícolas e na pressão de pastejo dos animais.

Neste contexto, este trabalho tem por objetivo avaliar as variaçôes nos atributos físicos do solo, em especial na agregação e resistência do solo à penetração, e carbono orgânico total de um Latossolo Vermelho argiloso da região de Cerrado sob sistema de integração lavoura-pecuária.

\section{MATERIAL E MÉTODOS}

O experimento foi realizado no município de Maracaju (MS), entre as coordenadas $21^{\circ} 37^{\prime} 55^{\prime \prime} \mathrm{S}, 55^{\circ} 08^{\prime} 55^{\prime \prime} \mathrm{W}$.
Nas áreas de estudo, o solo predominante foi classificado como Latossolo Vermelho (EMBRAPA, 2006), com textura argilosa (Tabela 1). O delineamento experimental utilizado foi o inteiramente casualizado, constituído de quatro glebas distintas próximas entre si. Estas glebas foram manejadas sob plantio direto integrando lavoura-pecuária. $\mathrm{Na}$ época da amostragem, as áreas estavam cultivadas com milho (Zea mays L.), braquiária (Brachiaria decumbens Stap), capim Tanzânia (Panicum maximum cv. Tanzânia), e como área testemunha utilizou-se um fragmento de Cerrado. A área cultivada com milho caracteriza-se pelo cultivo consecutivo há três anos com soja no verão e milho na safrinha (inverno), sendo anteriormente, cultivada com $B$. decumbens Stap, por um período de cinco anos. Nas áreas com $B$. decumbens e $P$. maximum cv. Tanzânia utilizam-se estas coberturas há sete anos, sendo anteriormente, ocupadas com soja em sistema de plantio direto por um período de 25 anos. Nas áreas com pastagem, os animais da raça Nelore, fase de engorda, eram manejados com pressão de pastejo de 5 animais ha ${ }^{-1}$, sendo mantidos em cada piquete até que a pastagem atingisse $20 \mathrm{~cm}$ de altura do solo.

Para realização das análises dos atributos físicos do solo, as amostras foram coletadas em quatro pontos para cada cobertura nas profundidades de $0-5,5-10$ e 10 $20 \mathrm{~cm}$. As amostras indeformadas de solo foram coletadas com auxílio de anel volumétrico com volume de $73,5 \mathrm{~cm}^{3}$ para determinação da densidade do solo, porosidade total, macro e microporosidade pelo método do anel volumétrico em mesa de tensão, segundo EMBRAPA (1997). A resistência do solo à penetração bem como a umidade volumétrica foram quantificadas em amostras saturadas, após

Tabela 1. Granulometria e classe textural do solo de Cerrado com diferentes coberturas vegetais manejado com sistema de integração lavoura-pecuária em Maracaju (MS)

\begin{tabular}{|c|c|c|c|c|}
\hline Cobertura do solo & $\begin{array}{c}\text { Areia } \\
\left(\mathrm{g} \mathrm{kg}^{-1}\right)\end{array}$ & $\begin{array}{l}\text { Argila } \\
\left(\mathrm{g} \mathrm{kg}^{-1}\right)\end{array}$ & $\begin{array}{c}\text { Silte } \\
\left(\mathrm{g} \mathrm{kg}^{-1}\right)\end{array}$ & Textura \\
\hline \multicolumn{5}{|c|}{$0-5 \mathrm{~cm}$} \\
\hline Milho & 203 & 471 & 326 & Argilosa \\
\hline Braquiária & 216 & 434 & 350 & Argilosa \\
\hline Tanzânia & 258 & 448 & 294 & Argilosa \\
\hline Cerrado & 204 & 449 & 347 & Argilosa \\
\hline Desvio-padrão & 23,50 & 15,51 & 24,37 & \\
\hline \multicolumn{5}{|c|}{$5-10 \mathrm{~cm}$} \\
\hline Milho & 201 & 495 & 304 & Argilosa \\
\hline Braquiária & 173 & 489 & 338 & Argilosa \\
\hline Tanzânia & 257 & 448 & 295 & Argilosa \\
\hline Cerrado & 191 & 444 & 365 & Argilosa \\
\hline Desvio-padrão & 32,89 & 24,38 & 28,82 & \\
\hline \multicolumn{5}{|c|}{$10-20 \mathrm{~cm}$} \\
\hline Milho & 188 & 502 & 310 & Argilosa \\
\hline Braquiária & 157 & 517 & 326 & Argilosa \\
\hline Tanzânia & 246 & 454 & 300 & Argilosa \\
\hline Cerrado & 179 & 476 & 345 & Argilosa \\
\hline Desvio-padrão & 34,85 & 25,57 & 18,68 & \\
\hline
\end{tabular}


6, 12 e 24 horas em mesa de tensão. Na determinação da resistência do solo à penetração utilizou-se penetrógrafo de bancada modelo MA-933.

Simultaneamente, para a análise de estabilidade de agregados, foram coletadas amostras em forma de torrão (indeformadas) nas profundidades de $0-5$ e $5-10 \mathrm{~cm}$. A estabilidade dos agregados foi determinada pelo método descrito por Kemper e Chepil (1965), utilizando-se $50 \mathrm{~g}$ de solo pré-umedecidos. Depois desse pré-umedecimento, a amostra foi mantida em repouso à temperatura ambiente por 30 minutos. Em seguida, essa amostra foi colocada no aparelho de oscilação vertical sobre um conjunto de peneiras de 4, 2, 1, 0,5 e 0,25 mm, conforme descrito por Yoder (1936). O nível de água no aparelho foi ajustado na posição mais alta das peneiras, para que a água cobrisse apenas o fundo da peneira de $4 \mathrm{~mm}$. Transcorridos 15 minutos, as porçóes retidas em cada peneira foram transferidas para cápsulas de alumínio com auxílio de jatos de água, e secas em estufa a $105^{\circ} \mathrm{C}$ para posterior pesagem. $\mathrm{O}$ diâmetro médio ponderado (DMP) dos agregados foi calculado a partir do somatório dos produtos entre o diâmetro médio de cada classe de agregado e a proporção da massa da amostra, que foi obtida por meio da divisão da massa de agregados retidos em cada peneira pela massa da amostra corrigida em termos de umidade.

Também, em cada área foram coletadas quatro amostras compostas formadas por dez amostras simples em uma área de $400 \mathrm{~m}^{2}$, nas profundidades de 0-5, 5-10 e 10-20 cm. Após a coleta, as amostras foram secas e peneiradas $(2 \mathrm{~mm})$, constituindo a terra fina seca ao ar (TFSA). Na TFSA o carbono orgânico total (COT) foi determinado pela oxidação com dicromato de potássio em meio sulfúrico e titulado com sulfato ferroso amoniacal, pelo método preconizado pela EMBRAPA (1997).
A análise de variância foi realizada pelo teste $\mathrm{F}$ e, quando significativo, as médias foram comparadas pelo teste de Scott-Knott $(\mathrm{p} \leq 0,05)$. Adicionalmente, foi realizada análise de correlação de Pearson entre os atributos físicos e carbono orgânico total do solo.

\section{RESULTADOS E DISCUSSÃO}

O manejo do solo rotacionando culturas e integrado com a pecuária alterou a porosidade, densidade e COT do solo (Tabela 2). Nas três profundidades estudadas, na área com cobertura de Cerrado, observaram-se maior porcentagem de poros totais, mais equilíbrio na distribuição entre macro e microporos, menor valor de densidade do solo e maiores teores de COT do solo. Nas áreas com cobertura de pastagem, principalmente Tanzânia, verificaram-se as menores porcentagens de poros totais, sendo os valores de $49,2 \%, 49,4 \%$ e $49,0 \%$ nas profundidades de $0-5$, 5-10 e 10-20 cm, respectivamente. Ainda, nas áreas com pastagens, a menor porosidade total do solo esta diretamente relacionada com a diminuição da porcentagem dos macroporos, sendo os menores valores observados na cobertura com Tanzânia $(9,40 \%)$ e braquiária $(6,60 \%)$, nas profundidades de $0-5$ e $5-10 \mathrm{~cm}$ respectivamente; valores aproximadamente $50 \%$ menor se comparado com os da vegetaçấo natural de Cerrado. A diminuição dos macroporos nas áreas com pastagens refletiu no aumento da densidade do solo com valores que variaram de 1,32 a $1,60 \mathrm{Mg} \mathrm{m}^{-3}$, ambos na profundidade de $0-5 \mathrm{~cm}$.

Nas profundidades de $0-5$ e $10-20 \mathrm{~cm}$, não houve diferença nos teores de COT entre a área cultivada com milho e as de pastagens. Já na profundidade de $5-10 \mathrm{~cm}$, na área com Tanzânia ocorreu o menor acúmulo de COT

Tabela 2. Porosidade, densidade e carbono orgânico total (COT) do solo de Cerrado com diferentes coberturas vegetais manejado com sistema de integração lavoura-pecuária em Maracaju (MS)

\begin{tabular}{|c|c|c|c|c|c|}
\hline Cobertura do solo & $\begin{array}{c}\text { Microporosidade } \\
\text { (\%) }\end{array}$ & $\begin{array}{c}\text { Macroporosidade } \\
(\%)\end{array}$ & $\begin{array}{c}\text { Porosidade total } \\
\text { (\%) }\end{array}$ & $\begin{array}{l}\text { Densidade do solo } \\
\left(\mathrm{Mg} \mathrm{m}^{-3}\right)\end{array}$ & $\begin{array}{c}\text { COT } \\
\left(\mathrm{g} \mathrm{kg}^{-1}\right)\end{array}$ \\
\hline \multicolumn{6}{|c|}{$0-5 \mathrm{~cm}$} \\
\hline Milho & $39,60 \mathrm{a}$ & $13,20 \mathrm{~b}$ & $52,40 \mathrm{a}$ & $1,50 \mathrm{a}$ & $20,38 \mathrm{~b}$ \\
\hline Braquiária & $40,30 \mathrm{a}$ & $11,60 \mathrm{c}$ & $52,00 \mathrm{a}$ & $1,32 \mathrm{~b}$ & $25,58 \mathrm{~b}$ \\
\hline Tanzânia & $39,80 \mathrm{a}$ & $9,40 \mathrm{~d}$ & $49,20 \mathrm{~b}$ & $1,60 \mathrm{a}$ & $20,51 b$ \\
\hline Cerrado & $34,00 \mathrm{~b}$ & $20,20 \mathrm{a}$ & $56,20 \mathrm{a}$ & $0,86 c$ & $36,26 \mathrm{a}$ \\
\hline \multicolumn{6}{|c|}{$5-10 \mathrm{~cm}$} \\
\hline Milho & $41,60 \mathrm{a}$ & $10,20 \mathrm{~b}$ & $51,80 \mathrm{a}$ & $1,52 \mathrm{a}$ & $20,15 \mathrm{a}$ \\
\hline Braquiária & $41,60 \mathrm{a}$ & $6,60 c$ & $48,40 \mathrm{~b}$ & $1,54 \mathrm{a}$ & $23,15 \mathrm{a}$ \\
\hline Tanzânia & $34,20 \mathrm{c}$ & $9,20 \mathrm{~b}$ & $49,40 \mathrm{~b}$ & $1,52 \mathrm{a}$ & $11,89 \mathrm{~b}$ \\
\hline Cerrado & $37,60 \mathrm{~b}$ & $15,80 \mathrm{a}$ & $53,40 \mathrm{a}$ & $1,12 b$ & $30,01 \mathrm{a}$ \\
\hline \multicolumn{6}{|c|}{$10-20 \mathrm{~cm}$} \\
\hline Milho & $42,80 \mathrm{a}$ & $9,40 \mathrm{~b}$ & $52,20 \mathrm{~b}$ & $1,56 \mathrm{a}$ & $17,57 \mathrm{~b}$ \\
\hline Braquiária & $41,00 \mathrm{~b}$ & $9,60 \mathrm{~b}$ & $50,60 \mathrm{c}$ & $1,44 \mathrm{a}$ & $15,49 b$ \\
\hline Tanzânia & $38,60 \mathrm{c}$ & $10,60 \mathrm{~b}$ & $49,00 \mathrm{c}$ & $1,50 \mathrm{a}$ & $11,69 b$ \\
\hline Cerrado & $37,00 \mathrm{c}$ & $17,80 \mathrm{a}$ & $54,80 \mathrm{a}$ & $0,96 \mathrm{~b}$ & $28,61 \mathrm{a}$ \\
\hline CV (\%) & 9,52 & 10,12 & 8,72 & 9,63 & 24,35 \\
\hline
\end{tabular}


$\left(11,89 \mathrm{~g} \mathrm{~kg}^{-1}\right)$, enquanto na área com braquiária e cultivada com milho os teores de COT foram semelhantes e não diferiram da área de Cerrado.

$\mathrm{O}$ pisoteio dos animais, pode ter sido o principal fator responsável pela compactação do solo nas camadas superficiais (aumento da densidade e diminuição da macroporosidade do solo) nas áreas de pastagem em comparação com o Cerrado. Lanzanova et al. (2007), verificaram que após três anos de pastejo, manejado sob sistema de integraçáo lavoura-pecuária, a compactação ficou restrita à camada de $0-0,05 \mathrm{~m}$, com valores de densidade do solo variando de 1,32 a $1,35 \mathrm{Mg} \mathrm{m}^{-3}$. Ainda os mesmos autores observaram que a redução do intervalo de pastoreio de 28 para 14 dias, diminuiu significativamente a macroporosidade e a porosidade total na camada superficial, passando, respectivamente, de 0,11 para 0,07 e de 0,56 para $0,51 \mathrm{dm}^{3} \mathrm{dm}^{-3}$.

No caso da cobertura com Tanzânia, os valores de compactação tiveram maior magnitude, atribuindo-se ao seu hábito de crescimento cespitoso, cujo percentual de solo descoberto entre touceiras é elevado, tornando o solo mais suscetível à ação da compactação superficial ocasionada pelo pisoteio dos animais durante o pastejo, conforme dados corroborados aos de outros autores (IMHOFF et al., 2000; Spera et al., 2009; MarChão et al., 2007).

$\mathrm{Na}$ área com plantio de milho nas camadas superficiais $(0-5$ e $5-10 \mathrm{~cm})$ houve melhoria na macroporosidade e porosidade total do solo em relaçáo às áreas com pastagens. No entanto, tal comportamento não foi observado para a densidade do solo, podendo ser explicado, em parte, pelo pouco tempo de cultivo soja/milho em plantio direto (três anos) antecedido por cinco anos de pastagem, ou à maior sensibilidade da macroporosidade em detectar alteraçóes da estrutura do solo, devido ao manejo adotado do que à densidade do solo. $\mathrm{O}$ aumento dos macroporos em sistema plantio direto é importante para a conservação do solo e da água, pois está diretamente relacionado com a melhoria da aeração e infiltração de água no solo. Andreola et al. (2000), trabalhando com cobertura de solo, observaram aumento de macroporos em relação aos microporos na camada de $10-15 \mathrm{~cm}$, sendo atribuído ao efeito das raízes da cultura do milho. Dexter (1991) relata que as raízes do milho, ao penetrarem, comprimem as partículas do solo, e com a morte e posterior decomposição formam os bioporos, que contribuem para o aumento da macroporosidade. Venzke Filho et al. (2004), em trabalho com sistema de plantio direto, verificaram a existência na camada de $0-10 \mathrm{~cm}$, de $36 \%$ e $30 \%$ de raízes de milho e soja respectivamente; a porcentagem de raízes finas de $28 \%$ no milho e $92 \%$ na soja ocasionam maior contato solo-raiz, refletindo na diminuição da densidade do solo e aumento da macroporosidade e porosidade total do solo, em comparação com sistemas de produção dessas culturas em monocultivo. Além disso, deve-se considerar no sistema soja/milho o aporte de resíduos vegetais da colheita dessas culturas, que condicionam melhoria nos atributos físicos do solo. Lanzanova et al. (2007), em manejo de solo integrando lavoura-pecuária, observaram aporte médio de matéria seca de soja variando de 3,77 a 4,52 $\mathrm{Mg} \mathrm{ha}^{-1}$ e de 9,50 a 12,75 $\mathrm{Mg} \mathrm{ha}^{-1}$ para milho, dependendo da pressáo de pastejo adotado.

A resistência do solo à penetração $(\mathrm{RP})$ e a umidade do solo proporcionam alteraçóes em função da rotação de culturas integradas com pecuária (Tabela 3). Em geral, nas três profundidades estudadas, os maiores e menores valores de RP do solo (da amostra saturada até aquela com permanência de 24 horas em mesa de tensão) ocorreram nas áreas com pastagens e Cerrado respectivamente. A RP do solo medida após 24 horas de permanência das amostras em mesa de tensão, que simula a capacidade de campo (água perdida dos macroporos), revelou valores de 2,05 e 1,3 $\mathrm{MPa}$, respectivamente, nas profundidades de $0-5 \mathrm{e}$ 10-20 cm, com cobertura de Tanzânia , e de 4,08 MPa na profundidade de $5-10 \mathrm{~cm}$ com braquiária. À medida que as amostras de solo tiveram sua umidade diminuída, os valores de RP do solo tenderam a aumentar ligeiramente, mais expressivamente nas áreas com pastagens; portanto, não é possível fazer associaçóes com valores, ou seja, em diferentes coberturas do solo verificaram-se valores de UM iguais com RP do solo discrepantes. Tal fato implica a existência de outros fatores relacionados ao manejo do solo, além de sua umidade, atuando no controle da RP do solo.

A umidade do solo saturado (UMs) sob cobertura de milho propiciou ou maiores valores, exceto na profundidade de 10 $20 \mathrm{~cm}$, dados condizentes com os de porosidade total do solo (Tabela 2). À medida que a água foi sendo retirada dos macroporos $\left(\mathrm{UM}_{24}\right)$, os teores no solo foram maiores sob cobertura das pastagens, exceto na profundidade de $0-5 \mathrm{~cm}$ que não diferiu dos valores observados no solo sob cobertura de milho.

De maneira geral, os maiores valores de RP ocorreram nas áreas de pastagens, podendo ser atribuídos ao pisoteio dos animais, como observado por LANZANOva et al. (2007), em trabalho com pastagem de inverno em sistema de integração lavoura-pecuária, cujos valores de RP foram de 2,49 e 2,61 MPa para os intervalos de pastejo de 28 e 14 dias respectivamente. Clark et al. (2004), em trabalho envolvendo o pastoreio em intervalo de 28 dias em resteva de lavoura de milho verificaram aumentos de $44 \%$ nos valores de RP em relação às áreas não pastejadas. Os valores de $\mathrm{RP}_{24}$ na camada de $0-5 \mathrm{~cm}$ para Tanzânia e 5-10 $\mathrm{cm}$ para braquiária foram superiores em relação ao limite crítico de 2 MPa proposto por TAYLOR et al. (1966). Lipiec e Hatano (2003) acrescentam que valores de RP variando de 1 a $1,7 \mathrm{MPa}$ começam a restringir o crescimento radicular, e que valores entre 3 e $4 \mathrm{MPa}$ causam paralisação do crescimento das raízes. No entanto, partes das variaçóes de RP observadas entre os tratamentos, além da umidade do solo, podem ser dependentes do tipo de solo (pedogênese) e da distribuição do tamanho de poros.

O manejo do solo com rotaçáo de culturas e integração com a pecuária alterou o tamanho dos agregados do 
solo (Tabela 4). Nas duas profundidades estudadas, ocorreu maior porcentagem de agregados de tamanho maior que $4 \mathrm{~mm}$, variando de 23,37 a 93,09\%, nas coberturas de Tanzânia e Cerrado respectivamente. O maior efeito sobre a diminuiçáo do tamanho de agregados ocorreu na área com Tanzânia, havendo menor quantidade de agregados maiores que $4 \mathrm{~mm}$, quando comparado com as outras coberturas. Por consequência, nas demais classes de tamanhos de agregados (de 2 a $4 \mathrm{~mm}$ até 0,25 a $0,5 \mathrm{~mm}$ ) houve maior porcentagem, na área com Tanzânia, proporcionando nas duas profundidades menor diâmetro ponderado dos agregados (Tabela 4).

A maior proporção de agregados com tamanhos menores na cobertura com Tanzânia causou reflexos nos demais atributos físicos do solo, como diminuição da macroporosidade e aumento da densidade do solo e RP do solo (Tabelas 2 e 3), podendo limitar o crescimento radicular da pastagem ou até mesmo a produtividade da cultura de grãos em sucessão, como observado por FLORES et al. (2007) para o rendimento da soja em sistema de plantio direto com integração lavoura-pecuária.

Houve correlação significativa entre alguns atributos físicos e COT do solo (Tabela 5), indicando que as variaçôes nos teores de COT proporcionam mudanças nos atributos físicos do solo.

A porosidade total do solo revelou correlação positiva $(\mathrm{r}=0,66)$ com a macroporosidade do solo, não havendo, portanto, correlação significativa com a microporosidade. Para densidade do solo, verifica-se correlação positiva com a microporosidade $(\mathrm{r}=0,61)$ e negativa com a macroporosidade $(\mathrm{r}=-0,80)$ e porosidade total $(\mathrm{r}=-0,37)$. A RP do solo após 24 horas em mesa de tensão correlacionou-se

Tabela 3. Resistência do solo à penetração e umidade volumétrica do solo de Cerrado com diferentes coberturas vegetais manejado com sistema de integração lavoura-pecuária em Maracaju (MS)

\begin{tabular}{|c|c|c|c|c|c|c|c|c|}
\hline \multirow{2}{*}{$\begin{array}{l}\text { Cobertura } \\
\text { do solo }\end{array}$} & \multicolumn{4}{|c|}{$\begin{array}{l}\text { Resistência do solo à penetração } \\
(\mathrm{MPa})\end{array}$} & \multicolumn{4}{|c|}{$\begin{array}{l}\text { Umidade do solo } \\
\left(\Theta, \mathrm{cm}^{3} \mathrm{~cm}^{-3}\right)\end{array}$} \\
\hline & $\mathbf{R P}_{\text {s }}$ & $\mathbf{R P}_{6}$ & $\mathbf{R P}_{12}$ & $\mathbf{R P}_{24}$ & $\mathrm{UM}_{\mathrm{s}}$ & $\mathrm{UM}_{6}$ & $\mathrm{UM}_{12}$ & $\mathrm{UM}_{24}$ \\
\hline \multicolumn{9}{|c|}{$0-5 \mathrm{~cm}$} \\
\hline Milho & $1,15 b$ & $0,72 b$ & $0,73 b$ & $1,06 \mathrm{a}$ & $0,62 a$ & $0,54 \mathrm{a}$ & $0,49 a$ & $0,42 a$ \\
\hline Braquiária & $1,91 \mathrm{a}$ & $2,17 \mathrm{a}$ & $1,73 a$ & $1,85 \mathrm{a}$ & $0,54 b$ & $0,47 b$ & $0,47 a$ & $0,45 a$ \\
\hline Tanzânia & $2,44 \mathrm{a}$ & $1,47 \mathrm{a}$ & $1,65 \mathrm{a}$ & $2,05 a$ & $0,56 \mathrm{~b}$ & $0,51 \mathrm{a}$ & $0,48 \mathrm{a}$ & $0,45 a$ \\
\hline Cerrado & $0,08 \mathrm{c}$ & $0,09 \mathrm{~b}$ & $0,06 \mathrm{c}$ & $0,23 \mathrm{~b}$ & $0,60 \mathrm{a}$ & $0,39 c$ & $0,39 \mathrm{~b}$ & $0,35 b$ \\
\hline \multicolumn{9}{|c|}{$5-10 \mathrm{~cm}$} \\
\hline Milho & $0,87 a$ & $0,50 \mathrm{~b}$ & $0,50 \mathrm{~b}$ & $0,51 \mathrm{~b}$ & $0,62 a$ & $0,53 \mathrm{a}$ & $0,48 a$ & $0,41 b$ \\
\hline Braquiária & $1,21 \mathrm{a}$ & $1,94 \mathrm{a}$ & $1,60 \mathrm{a}$ & $4,08 a$ & $0,50 \mathrm{~b}$ & $0,46 b$ & $0,46 a$ & $0,44 a$ \\
\hline Tanzânia & $1,53 \mathrm{a}$ & $1,85 \mathrm{a}$ & $1,28 a$ & 1,42 b & $0,54 b$ & $0,51 \mathrm{a}$ & $0,48 a$ & $0,45 a$ \\
\hline Cerrado & $0,21 \mathrm{a}$ & $0,43 \mathrm{~b}$ & $0,12 b$ & $0,20 \mathrm{~b}$ & $0,56 b$ & $0,41 \mathrm{~b}$ & $0,42 b$ & $0,38 \mathrm{~b}$ \\
\hline \multicolumn{9}{|c|}{$10-20 \mathrm{~cm}$} \\
\hline Milho & $1,16 \mathrm{a}$ & $0,92 \mathrm{a}$ & $0,89 a$ & $0,95 a$ & $0,57 a$ & $0,38 c$ & $0,40 \mathrm{~b}$ & $0,36 \mathrm{~b}$ \\
\hline Braquiária & $1,74 \mathrm{a}$ & $1,38 \mathrm{a}$ & $1,14 \mathrm{a}$ & $1,14 \mathrm{a}$ & $0,53 \mathrm{a}$ & $0,46 b$ & $0,48 a$ & $0,46 a$ \\
\hline Tanzânia & $1,09 \mathrm{a}$ & $1,29 \mathrm{a}$ & $1,17 \mathrm{a}$ & $1,31 \mathrm{a}$ & $0,53 a$ & $0,52 \mathrm{a}$ & $0,48 a$ & $0,45 a$ \\
\hline Cerrado & $0,11 b$ & $0,04 \mathrm{~b}$ & $0,08 \mathrm{~b}$ & $0,19 a$ & $0,58 \mathrm{a}$ & $0,41 c$ & $0,42 b$ & $0,37 b$ \\
\hline CV (\%) & 56,21 & 54,65 & 47,92 & 121,73 & 7,51 & 7,42 & 7,93 & 8,45 \\
\hline
\end{tabular}

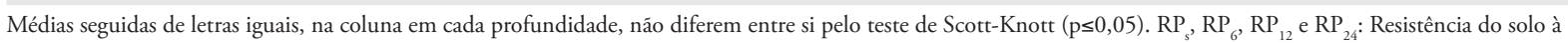
penetração em amostras saturada, e após 6, 12 e 24 horas em mesa de tensão respectivamente. $U_{\mathrm{s}_{\mathrm{s}}}, \mathrm{UM}_{6}, \mathrm{UM}_{12}$ e $\mathrm{UM}_{24}$ : umidade do solo em amostras saturadas, e após 6, 12 e 24 horas em mesa de tensão respectivamente.

Tabela 4. Porcentagem de tamanho dos agregados do solo de Cerrado com diferentes coberturas vegetais manejado com sistema de integração lavoura-pecuária em Maracaju (MS)

\begin{tabular}{|c|c|c|c|c|c|c|}
\hline Cobertura do solo & $>4$ mm & 2 a $4 \mathrm{~mm}$ & 1 a $2 \mathrm{~mm}$ & 0,5 a $1 \mathrm{~mm}$ & 0,25 a $0,5 \mathrm{~mm}$ & $\begin{array}{l}\text { DMP } \\
(\mathrm{mm})\end{array}$ \\
\hline \multicolumn{7}{|c|}{$0-5 \mathrm{~cm}$} \\
\hline Milho & $84,52 \mathrm{a}$ & $9,15 \mathrm{a}$ & $2,77 \mathrm{~b}$ & $2,05 b$ & $1,50 \mathrm{~b}$ & $3,72 a$ \\
\hline Braquiária & $92,11 \mathrm{a}$ & $4,83 \mathrm{~b}$ & $1,90 \mathrm{~b}$ & $0,92 \mathrm{~b}$ & $0,66 \mathrm{~b}$ & $3,86 a$ \\
\hline Tanzânia & $66,44 \mathrm{~b}$ & $12,22 \mathrm{a}$ & $6,08 \mathrm{a}$ & $7,73 \mathrm{a}$ & $7,52 \mathrm{a}$ & $3,20 \mathrm{~b}$ \\
\hline Cerrado & $89,75 \mathrm{a}$ & $7,22 \mathrm{~b}$ & $1,68 \mathrm{~b}$ & $0,78 \mathrm{~b}$ & $0,55 b$ & $3,84 \mathrm{a}$ \\
\hline \multicolumn{7}{|c|}{$5-10 \mathrm{~cm}$} \\
\hline Milho & $82,75 \mathrm{a}$ & 9,46 b & $2,70 \mathrm{~b}$ & $2,55 \mathrm{~b}$ & $2,52 \mathrm{~b}$ & $3,66 a$ \\
\hline Braquiária & 86,11 a & $8,36 \mathrm{~b}$ & $2,59 \mathrm{~b}$ & $1,91 \mathrm{~b}$ & $1,01 \mathrm{~b}$ & $3,75 a$ \\
\hline Tanzânia & $23,37 b$ & 19,29 a & $18,61 \mathrm{a}$ & $22,40 \mathrm{a}$ & $16,37 \mathrm{a}$ & $2,02 b$ \\
\hline Cerrado & 93,09 a & $4,34 \mathrm{~b}$ & $1,43 b$ & $0,72 \mathrm{~b}$ & $0,40 \mathrm{~b}$ & $3,88 a$ \\
\hline CV (\%) & 11,45 & 34,12 & 50,14 & 54,43 & 48,97 & 6,37 \\
\hline
\end{tabular}

Médias seguidas de letras iguais, na coluna em cada profundidade, não diferem entre si pelo teste de Scott-Knott, p $\leq 0,05$. DMP: diâmetro médio ponderado de agregados. 
Tabela 5. Correlaçấo de Pearson (r) entre os atributos físicos e COT do solo de Cerrado com diferentes coberturas vegetais manejado com sistema de integração lavoura-pecuária em Maracaju (MS)

\begin{tabular}{|c|c|c|c|c|c|c|c|c|c|c|c|c|c|c|}
\hline & Mi & $\mathrm{Ma}$ & Pt & Ds & СOT & RPs & $\mathbf{R P}_{24}$ & UMs & $\mathrm{UM}_{24}$ & $>4$ & $2 / 4$ & $1 / 2$ & $0,5 / 1$ & $0,25 / 0,5$ \\
\hline $\mathrm{Ma}$ & $-0,54^{*}$ & & & & & & & & & & & & & \\
\hline Pt & $0,28^{\text {ns }}$ & $0,66^{*}$ & & & & & & & & & & & & \\
\hline Ds & $0,61^{*}$ & $-0,80^{*}$ & $-0,37^{* *}$ & & & & & & & & & & & \\
\hline COT & $-0,12^{\text {ns }}$ & $0,51^{*}$ & $0,46^{*}$ & $-0,56^{*}$ & & & & & & & & & & \\
\hline RPs & $0,25^{\text {ns }}$ & $-0,49^{*}$ & $-0,33^{* *}$ & $0,71^{*}$ & $-0,37^{* *}$ & & & & & & & & & \\
\hline $\mathrm{RP}_{24}$ & $0,28^{\text {ns }}$ & $-0,48^{*}$ & $-0,29^{\text {ns }}$ & $0,38^{* *}$ & $-0,05^{\text {ns }}$ & $0,21^{\text {ns }}$ & & & & & & & & \\
\hline UMs & $-0,04^{\text {ns }}$ & 0,39 ** & $0,41^{*}$ & $-0,37^{* *}$ & $0,09^{\text {ns }}$ & $-0,40^{* *}$ & $-0,55^{*}$ & & & & & & & \\
\hline $\mathrm{UM}_{24}$ & $0,29^{\text {ns }}$ & $-0,56^{*}$ & $-0,37^{* *}$ & $0,55^{*}$ & $-0,10^{\text {ns }}$ & $0,56^{*}$ & $0,14^{\text {ns }}$ & $-0,13^{\text {ns }}$ & & & & & & \\
\hline$>4$ & $0,36 * *$ & $0,37^{* *}$ & $0,74^{*}$ & $-0,36^{* *}$ & $0,45^{*}$ & $-0,33^{* *}$ & $-0,02^{\mathrm{ns}}$ & $0,17^{\mathrm{ns}}$ & $-0,37^{* *}$ & & & & & \\
\hline $2 / 4$ & $-0,22^{\text {ns }}$ & $-0,34^{* *}$ & $-0,59^{*}$ & $0,41^{* *}$ & $-0,42^{*}$ & $0,34^{* *}$ & $0,05^{\text {ns }}$ & $-0,17^{\text {ns }}$ & $0,37^{* *}$ & $-0,92^{*}$ & & & & \\
\hline $1 / 2$ & $-0,40^{* *}$ & $-0,34^{* *}$ & $-0,74^{*}$ & $0,32^{* *}$ & $-0,45^{*}$ & $0,27^{\text {ns }}$ & $-0,02^{\text {ns }}$ & $-0,16^{\text {ns }}$ & $0,35^{* *}$ & $-0,98^{*}$ & $0,86^{*}$ & & & \\
\hline $0,5 / 1$ & $-0,40^{* *}$ & $-0,37^{* *}$ & $-0,77^{*}$ & $0,33^{* *}$ & $-0,45^{*}$ & $0,29^{\text {ns }}$ & $0,02^{\text {ns }}$ & $-0,15^{\text {ns }}$ & $0,35^{* *}$ & $-0,98^{*}$ & $0,85^{*}$ & $0,99^{*}$ & & \\
\hline $0,25 / 0,5$ & $-0,36^{* *}$ & $-0,38^{* *}$ & $-0,75^{*}$ & $0,36^{* *}$ & $-0,44^{*}$ & $0,38^{* *}$ & $0,02^{\text {ns }}$ & $-0,17^{n s}$ & $0,37^{* *}$ & $-0,98^{*}$ & $0,86^{*}$ & $0,96^{*}$ & $0,97^{*}$ & \\
\hline DMP & $0,38^{* *}$ & $0,37^{* *}$ & $0,76^{*}$ & $-0,35^{* *}$ & $0,45^{*}$ & $-0,32^{* *}$ & $-0,02^{\text {ns }}$ & $0,16^{\text {ns }}$ & $-0,37^{* *}$ & $0,99^{*}$ & $-0,88^{*}$ & $-0,99 *$ & $-0,99^{*}$ & $-0,99$ \\
\hline
\end{tabular}

Mi: microporosidade. Ma: macroporosidade. Pt: porosidade total do solo. Ds: densidade do solo. COT: carbono orgânico total. RPs: resistência à penetração do solo saturado. $\mathrm{RP}_{24}$ : resistência do solo à penetraçấo após 24 horas na mesa de tensão. UMs: umidade do solo saturado. UM 24 : umidade do solo após 24 horas na mesa de tensão. >4: porcentagem de agregados com tamanho maior que $4 \mathrm{~mm}$. 2/4: porcentagem de agregados com diâmetro entre 2 e $4 \mathrm{~mm}$. 1/2: porcentagem de agregados com diâmetro entre 1 e $2 \mathrm{~mm}$. 0,5/1: porcentagem de agregados com diâmetro entre 0,5 e $1 \mathrm{~mm}$. 0,25/0,5: porcentagem de agregados com diâmetro entre 0,25 e 0,5 mm. ns: năo significativo a $5 \%$. *, ${ }^{* *}$ significativo a $1 \%$ e $5 \%$ respectivamente, pelo teste $\mathrm{t}$.

negativamente com a macroporosidade do solo $(\mathrm{r}=-0,48)$ e positivamente com a densidade do solo $(\mathrm{r}=0,38)$. Já a umidade do solo após 24 horas, em mesa de tensão, revelou correlaçáo negativa com macroporosidade $(r=-0,56)$ e porosidade total do solo $(\mathrm{r}=-0,37)$, e positiva com densidade $(r=0,55)$ e RP do solo saturado $(r=0,56)$. O diâmetro médio dos agregados propiciou correlaçâo positiva principalmente com porosidade total do solo $(\mathrm{r}=0,76)$, carbono orgânico total $(\mathrm{r}=0,45)$, e negativa com a densidade do solo $(r=-0,32)$; ou seja, o aumento ou manutenção nos teores de COT via plantio direto integrando lavoura-pecuária proporciona aumento da porosidade do solo (principalmente na macroporosidade), na proporção de agregados de tamanhos maiores que $4 \mathrm{~mm}$ e no aumento do diâmetro médio ponderado dos agregados, com consequente diminuiçấo da densidade e da resistência do solo à penetração.

Além de agregados maiores, é interessante a utilização de sistemas de manejo que proporcionem agregados mais resistentes (maior índice de estabilidade), pois manterão a estrutura do solo sem grandes alteraçóes quando submetidas a forças externas, como operaçóes mecanizadas, pisoteio de animais, bem como diminui a perda de solo por erosão. Salton et al. (2008), em trabalho com Latossolo sob diferentes manejos e coberturas do solo, verificaram correlação positiva ( $\mathrm{p}<0,0001)$ entre COT e índice de estabilidade de agregados; sendo os maiores valores observados nas áreas com cultivo permanente de Brachiaria decumbens, seguido da rotação soja (dois anos) B. decumbens (dois anos).

No presente trabalho, observa-se que o cultivo de $B$. decumbens por sete anos (após 25 anos com soja sob sistema de plantio direto) proporcionou melhoria nos teores de COT, RP, densidade e agregação do solo, valores próximos à vegetação natural de Cerrado, diferentemente quando se utilizou Panicum maximum cv. Tanzânia. Ainda, substituindo a pastagem $B$. decumbens, após cinco anos de cultivo, por culturas anuais de soja no veráo e milho no inverno, percebe-se com o tempo de cultivo (três anos) diminuição na agregação do solo. Este fato sinaliza para estudos mais detalhados quanto ao tempo de rotação ou de permanência de cada cobertura, quer seja cultura anual ou pastagem.

\section{CONCLUSÃO}

A substituição da vegetação natural de Cerrado pela atividade de integração lavoura-pecuária altera os atributos físicos do solo, com diminuição da porosidade total, macroporosidade, carbono orgânico total e tamanho dos agregados do solo, bem como aumenta a densidade do solo e resistência do solo à penetração.

Nas áreas manejadas sob sistema de plantio direto integrando lavoura-pecuária e com pastagem Brachiaria decumbens observam-se menores valores de densidade do solo e maiores teores de carbono orgânico total.

Nas áreas com as pastagens Brachiaria decumbens e Panicum maximum cv. Tanzânia, verificam-se os maiores valores de resistência do solo à penetraçáo.

$\mathrm{Na}$ área com Panicum maximum cv. Tanzânia, notam-se os menores valores de diâmetro médio ponderado de agregados do solo.

\section{AGRADECIMENTOS}

Os autores agradecem à Fundação de Apoio ao Desenvolvimento do Ensino, Ciência e Tecnologia do 
Estado de Mato Grosso do Sul - FUNDECT, Fundect/ CNPq 02/2007-PPP Processo 23/200.110/2008, e ao CNPq projeto "casadinho" processo 620029/20080, pelo apoio financeiro.

\section{REFERÊNCIAS}

ANDREOLA, F.; COSTA, L.M.; OLSZEVSKI, N. Influência da cobertura vegetal de inverno e da adubação orgânica e ou mineral sobre as propriedades físicas de uma Terra Roxa Estruturada. Revista Brasileira de Ciência do Solo, v.24, p.857-865, 2000.

BALBINOT JÚNIOR, A.A.; MORAES, A.; VEIGA, M.; PELISSARI, A.; DIECKOW, J. Integração lavoura-pecuária: intensificação de usos de terras agrícolas. Ciência Rural, v.39, p.1925-1933, 2009.

BALBINO, L.C.; BRUAND, A.; COUSIN, I.; BROSSARD, M.; QUÉTIN, P.; GRIMALDI, M. Change in the hydraulic properties of a Brazilian clay Ferralsol on clearing for pasture. Geoderma, v.120, p.297-307, 2004.

BRONICK, C.J.; LAL, R. Soil structure and management: A review. Geoderma, v.124, p.3-22, 2005.

CLARK, J.T.; RUSSELL, J.R.; KARLEN, D.L.; SINGLETON, P.L.; BUSBY, W.D.; PETERSON, B.C. Soil surface property and soybean yield response to corn stover grazing. Agronomy Journal, v.96, p.1364-1371, 2004.

CORRÊA, J.C. Efeito de sistemas de cultivo na estabilidade de agregados de um Latossolo Vermelho-Amarelo em Querência, MT. Pesquisa Agropecuária Brasileira, v.37, p.203-209, 2002.

DEXTER, A.R. Amelioration of soil by natural processes. Soil and Tillage Research, v.20, p.87-100, 1991.

EDWARDS, A.P.; BREMMER, J.M. Dispersion of soil particles by sonic vibration. European Journal of Soil Science, v.18, p.4763, 1967.

EMERSON, W.W. The structure of soil crumbs. European Journal of Soil Science, v.10, p.235-244, 1959.

EMBRAPA - EMPRESA BRASILEIRA DE PESQUISA AGROPECUÁRIA. Centro Nacional de Pesquisa de Solos. Manual de métodos de análises de solos. 2.ed. Rio de Janeiro: Embrapa Solos, 1997. 212p.

EMBRAPA - EMPRESA BRASILEIRA DE PESQUISA AGROPECUÁRIA. Centro Nacional de Pesquisa de Solos. Sistema Brasileiro de Classificação de Solos. Rio de Janeiro, 2006. 306p.

FLORES, J.P.C.; ANGHINONI, I.; CASSOL, L.C.; CARVALHO, P.C.F.; LEITE, J.G.D.B.; FRAGA, T.I. Atributos físicos do solo e rendimento de soja em sistema plantio direto em integração lavourapecuária com diferentes pressōes de pastejo. Revista Brasileira de Ciência do Solo, v.31, p.771-780, 2007.

IMHOFF, S.; SILVA, A.P.; TORMENA, C.A. Aplicaçáo da curva de resistência do solo à penetraçáo no controle da qualidade física de um solo sob pastagem. Pesquisa Agropecuária Brasileira, v.35, p.1493-1500, 2000.

KEMPER, W.D.; CHEPIL, W.S. Size distribution of aggregates. In: BLACK,C.A.; EVANS, D.D.; WHITE, J.L.; ENSMINGER, L.E.; CLARK, F.E. (Ed.). Methods of soil analysis: physical and mineralogical properties, including statistics of measurement and sampling. Part 1. Madison: American Society of Agronomy, 1965. p.499-510.

LANZANOVA, M.E.; NICOLOSO, R.S.; LOVATO, T.; ELTZ, F.L.F.; AMADO, T.J.C.; REINERT, D.J. Atributos físicos do solo em sistema de integração lavoura-pecuária sob plantio direto. Revista Brasileira de Ciência do Solo, v.31, p.1131-1140, 2007.

LIPIEC, J.; HATANO, R. Quantification of compaction effects on soil physical properties and crop growth. Geoderma, v.116, p.107136, 2003.

MARCHÃO, R.L.; BALBINO, L.C.; SILVA, E.M.; SANTOS JUNIOR, J.D.G.; DE SÁ, M.A.C.; VILELA, L.; BECQUER, T. Qualidade física de um Latossolo Vermelho sob sistema de integração lavoura-pecuária no cerrado. Pesquisa Agropecuária Brasileira, v.42, p.873-882, 2007.

MIELNICZUK, J.; BAYER, C.; VEZZANI, F.; LOVATO, T.; FERNANDES, F.F; DEBARBA, L. Manejo de solo e culturas e sua relação com estoques de carbono e nitrogênio do solo. In: CURI, N.; MARQUES, J.J.; GUILHERME, L.R.G.; LIMA, J.M.; LOPES, A.S.S.; ALVAREZ V., V.H. (Ed.). Tópicos em ciência do solo. Viçosa, MG: Sociedade Brasileira de Ciência do Solo, 2003. v.3, p.209-248.

SALTON, J.C.; MIELNICZUK, J.; BAYER, C.; BOENI, M.; CONCEIÇÃO, P.C.; FABRÍCIO, A.C.; MACEDO, M.C.M.; $\mathrm{BROCH}, \mathrm{D}$. Agregação e estabilidade de agregados do solo em sistemas agropecuários em Mato Grosso do Sul. Revista Brasileira de Ciência do Solo, v.32, p.11-21, 2008.

SPERA, S.T.; SANTOS, H.P.; FONTANELI, R.S.; TOMM, G.O. Efeito de pastagens de inverno e de verão em características físicas de solo sob plantio direto. Ciência Rural, v.36, p.1193-1200, 2006.

SPERA, S.T.; SANTOS, H.P.; FONTANELI, R.S.; TOMM, G.O. Integração lavoura e pecuária e os atributos físicos de solo manejado sob sistema plantio direto. Revista Brasileira de Ciência do Solo, v.33, p.129-136, 2009.

SIX, J.; BOSSUYT, H.; DEGRYZE, S.; DENEF, K. A history of research on the link between (micro) aggregates, soil biota, and soil organic matter dynamics. Soil and Tillage Research, v.79, p.7-31, 2004.

TAYLOR, H.M.; ROBERTSON, G.M.; PARKER, J.J. Soil strength root penetration relations for medium to coarse textured soil materials. Soil Science, v.102, p.18-22, 1966.

VENZKE FILHO, S.; FEIGL, B.; PICCOLO, M.; FANTE JUNIOR, L.; NETO, M.; CERRI, C. Root systems and microbial biomass under no-tillage system. Scientia Agricola, v.61, p.529$537,2004$.

YODER, R.E. A direct method of aggregate analysis of soil and a study of the physical nature of erosion losses. Journal of the American Society of Agronomy, v.28, p.337-351, 1936. 